\title{
Role of Ultrasonography in Diagnosing Acute Cholecystitis and Correlation with Intra-operative Findings
}

\author{
Bal Jaskaran Singh ${ }^{* 1}$, Sudershan Kapoor ${ }^{2}$
}

${ }^{1}$ Third Year Post-graduate Student, Department of Surgery, Govt. Medical College, Amritsar

${ }^{2}$ Professor and Head, Department of Surgery, Govt. Medical College, Amritsar

\section{Corresponding Author}

Bal Jaskaran Singh

Third Year Post-graduate Student, Department of Surgery,

Govt. Medical College, Amritsar

\begin{abstract}
Background: $90-95 \%$ of cases of acute cholecystitis are caused due to gall stones, i.e. calculous cholecystitis. Rest of the 5-10\% cases are caused without the presence of stones, i.e. acalculous cholecystitis. Diagnosis of acute cholecystitis involves clinical, laboratory, and radiographic findings especially by ultrasonography. Aim: The aim of the study is to evaluate role of ultrasonography in diagnosing acute cholecystitis and correlation with intra-operative findings. Material and Methods: The present study was conducted in the Department of Surgery, Govt. Medical College, Amritsar. A sample size of 50 patients was taken who were diagnosed as cases of acute cholecystitis either clinically or radiologically referred to the department. $\underline{\text { Results: }}$ The mean age of presentation was 54.94 years. It was more common in females than males and more common among married females. On USG abdomen, 92\% cases had calculous cholecystitis and $8 \%$ had acalculous cholecystitis. Intraoperatively, most common finding was adhesions. It was present in 40 patients (95.24\%) and increased wall thickness was present in 37 cases (88.09\%). The sensitivity and specificity of ultrasonography in our study was $97.62 \%$ and $62.5 \%$ respectively. Conclusion: The number of patients presenting with acute cholecystitis is increasing because of the increased awareness. With improved healthcare facilities and newer techniques, complications have declined substantially with reduced mortality and morbidity.
\end{abstract}

Keywords: Acute cholecystitis, USG.

\section{Background}

Acute cholecystitis is the inflammation of the gall bladder, which is frequently encountered by surgeons in the emergency setting. In acute calculous cholecystitis there is blockage of bile flow and the gall bladder becomes enlarged, red and tense. ${ }^{[1]}$

Acalculous cholecystitis is typically seen in hospitalised and critically ill patients, immune-compromised, patients receiving chemotherapy, TPN, patients of major trauma and burns. ${ }^{[2]}$

Gall stones are present in $10-15 \%$ of adults in developed countries. ${ }^{[3]}$ According to Indian Journal of Community Medicine (2011), 24\% of people suffering from gall stone disease have acute cholecystitis in India.

Complete blood count, C-reactive protein (CRP) and liver function tests (bilirubin and aminotransferases), are the common blood investigations required. The advent of and subsequent improvement in various imaging modalities has aided in the evaluation and diagnosis of acute cholecystitis. Plain abdominal radiographs are not of much usefulness in calculous cholecystitis because more than $90 \%$ of gall stones are radiolucent. So, X-rays show radio-opaque gall stones in only about $10 \%$ of cases of acute cholecystitis. In emphysematous cholecystitis, gas within the gallbladder wall can be visualised on X-rays.

Ultrasonography (USG) and Computed Tomography (CT) are now commonly available and used. Ultrasound scanning is the investigation of choice. Sonograms typically show pericholecystic fluid (fluid around the gall bladder), distended gall bladder (long axis $\geq 8 \mathrm{~cm}$, short axis $\geq 4 \mathrm{~cm}$ ), oedematous and thickened gall bladder wall (over $3.5 \mathrm{~mm}$ ), gall stones, and dilatation of bile duct. Murphy's sign can be elicited on ultrasound examination. ${ }^{[4]}$

The treatment of choice in acute cholecystitis is surgical removal of gall bladder, i.e Cholecystectomy. ${ }^{[5]}$ It can be either Open or Laparoscopic. Early cholecystectomy is done within 7 days of onset of symptoms. Delayed cholecystectomy is done after 6 weeks of onset of symptoms. In recent years, several studies aimed to determine the optimal timing of surgery for acute cholecystitis, showing a clear benefit in performing early rather than delayed cholecystectomy. ${ }^{[6]}$ 


\section{Aims and Objectives}

1. To study the ultrasonographic findings in Acute cholecystitis.

2. To find correlation of ultrasonographic findings with intra-operative findings in Acute cholecystitis.

\section{Material and Methods}

This study was done on 50 cases of Acute cholecystitis diagnosed clinically or radiologically admitted or referred to surgery department of Govt. Medical college / Guru Nanak Dev Hospital, Amritsar.

The patients were assessed clinically at presentation. A note of all the details such as age, sex, marrital status, date of onset of symptoms, date of admission and date of operation were made. Detailed history and clinical examination were done. Patient was subjected to radiological investigations in the form of ultrasound abdomen and findings were noted. All patients who undergo surgery were evaluated. All the intraoperative findings were studied. Study of the ultrasonographic findings and their correlation with intra-operative findings was done.

\section{Inclusion Criteria:}

1. All cases of Acute cholecystitis who give informed consent will be considered for study irrespective of age and sex.

\section{Exclusion Criteria:}

2. Cases of Acute cholecystitis along with cirrhosis and portal hypertension will not be considered for the study.

3. Cases of Acute cholecystitis along with stones in the common bile duct will not be considered for the study.

\section{Results}

The majority of cases of acute cholecystitis presented in the age group of 50-59 years (34\%). It was seen that acute cholecystitis was largely more common in females (82\%) than males (18\%), female to male ratio being 4.6:1. Married population (90\%) suffered more from acute cholecystitis than unmarried population $(10 \%)$. Early cholecystectomy was preferred over delayed cholecystectomy. Early cholecystectomy was done in 44 cases $(88 \%)$ and delayed cholecystectomy was done in only 6 cases (12\%). In this study 45 patients $(90 \%)$ had clinical features suggestive of acute cholecystitis, 44 patients (88\%) were diagnosed as acute cholecystitis radiologically (on Ultrasonography/CT scan/HIDA) and 42 patients (84\%) were confirmed as acute cholecystitis intraoperatively.

Ultrasonography is the primary imaging modality for assessment of acute cholecystitis. It is an accurate, safe, relatively inexpensive, and readily accessible imaging modality. All the 50 patients underwent ultrasonography (USG) abdomen. On USG abdomen, 92\% cases had calculous cholecystitis and $8 \%$ had acalculous cholecystitis. 54\% patients had increased gall bladder wall thickness, $46 \%$ had pericholecystic collection and $78 \%$ cases had positive Murphy's sign, suggestive of acute cholecystitis. The sensitivity and specificity of ultrasonography was $97.62 \%$ and $62.5 \%$ respectively. The sensitivity and specificity of ultrasonographic Murphy's sign was $85.71 \%$ and $62.5 \%$ respectively.

Open cholecystectomy was done in $78 \%$ of the cases and Laparoscopic cholecystectomy was done in $22 \%$ cases. Conversion to open surgery was done in only 1 case $(9.09 \%)$. Among 42 patients diagnosed as acute choecystitis, most common finding was adhesions. It was present in 40 patients $(95.24 \%)$. Increased wall thickness was present in 37 cases (88.09\%). In 20 patients (47.62\%) pericholecystic collection was present. Empyema of the gall bladder was present in 10 cases $(23.81 \%)$. Gangrene was present in 3 patients $(7.14 \%)$. Fistulous connection with gut was present in 2 patients $(4.76 \%)$, one with the duodenum and one with transverse colon. 37 patients presented clinically as acute cholecystitis, were diagnosed as acute cholecystitits radiologically and confirmed as acute cholecystitis intraoperatively. 38 patients had clinical features of acute cholecystitis and were confirmed intraoperatively as acute cholecystitis. 41 patients had probable diagnosis of acute cholecystitis on radiological investigation and were confirmed as acute cholecystitis intraoperatively.

\section{Discussion}

The majority of the patients belonged to the age group of 50-69 years $(62 \%)$, the highest incidence of acute cholecystitis in our study was found in the sixth decade (34\%). Our results are similar with the study done by Kimura, Yasutoshi et al (2016) which reported the frequency of acute cholecysitis is highest in people age 50-69 years old.7 Mean age of presentation in our study was 54.94 years (TABLE I). It is similar to the study done by Hwang $\mathrm{H}$. et al in 2014 that also showed the mean age for acute cholecystitis to be 55.5 years. ${ }^{[8]}$

Female to male ratio in our study was 4.6:1 (TABLE I). In study conducted by Rajkishore Singh et al in 2016, the female to male ratio was found to be $4.5: 1 .^{[9]}$ In the present study, 90\% of the patients were married and the remaining $10 \%$ were unmarried persons (TABLE I). A study by Rains AJH and Ritchie HD back in 1978 suggests that the high incidence among these multiparous women may be due to gall bladder relaxation and dilatation, which may progressively increase with each pregnancy, resulting in increased gall bladder volume and emptying. ${ }^{[10]}$

Table I: Socio-demographic variables

\begin{tabular}{|l|c|}
\hline Mean Age & 54.94 YEARS \\
\hline Gender & \\
\hline Male & $18 \%$ \\
\hline Female & $82 \%$ \\
\hline Marital Status & \\
\hline Married & $90 \%$ \\
\hline Unmarried & $10 \%$ \\
\hline
\end{tabular}

In our study, all the 50 patients (100\%) underwent Ultrasonography as the initial radiological investigation. In this study, on Ultrasonography, 46 patients (92\%) had calculous cholecystitis and 4 patients (8\%) had acalculous cholecystitis (TABLE II). Our findings correlate with study performed by Mima Maychet B. Sangma and Fremingston Marak (2016) who concluded that $94 \%$ of the cases were acute calculous cholecystitis and $6 \%$ of the case were acute acalculous cholecystitis. ${ }^{[11]}$ In our study, increased gall bladder wall thickness was found in 27 cases 


\section{International Journal of Innovative Research in Medical Science (IJIRMS) Volume 03 Issue 12 Dec 2018, ISSN: 2455-8737, Imp. Factor - 4.102 Available online at - $\underline{w w w . i j i r m s . i n}$}

(54\%) of acute cholecystitis (TABLE II). Alper Bilal Özkardeş et al (2014) in their study found that $74 \%$ of the cases of acute cholecystitis had increased wall thickness. ${ }^{[12]}$

In our study, pericholecystic fluid collection was present in 23 patients (46\%) (TABLE II). This finding is comparable to the finding in study done by Alper Bilal Özkardeş et al (2014) in which pericholecystic fluid collection was present in $48 \%$ of the patients on ultrasonography. ${ }^{[12]}$

Table II: Ultrasonographic findings

\begin{tabular}{|l|c|c|}
\hline Findings & $\begin{array}{c}\text { No. of Patients } \\
(\mathbf{n = 5 0})\end{array}$ & Percentage \\
\hline Calculous & 46 & 92.00 \\
\hline Acalculous & 4 & 8.00 \\
\hline Increased Wall Thickness & 27 & 54.00 \\
\hline Pericholecystic Collection & 23 & 46.00 \\
\hline Murphy's Sign & 39 & 78.00 \\
\hline
\end{tabular}

In this study ultrasonographic murphy's sign was positive in 39 cases. In this study, adhesions were the most common intraoperative finding. Adhesions were present in $95.24 \%$ of cases (TABLE III). The gall bladder wall thickness was increased in $88.09 \%$ cases (TABLE III). David F. et al (2012) in their study found that adhesions were most common intra-operative finding in acute cholecystitis and were present in $92.6 \%$ of the cases ${ }^{[13]}$ So, our results are in correlation with this study. Our results are comparable to study of Rosen CL et al (2001), who in their study in patients of acute cholecystitis found out that sensitivity of ultrasonography for diagnosis was $91 \%$, and specificity was $66 \%$. ${ }^{[14]}$

Pericholecystic fluid collection was present intra-operatively in $47.62 \%$ of the cases of acute cholecystitis in our study (TABLE III). Our results are in correlation with Mika Shapira-Rootman et al, who in their study (2015) also found out that during surgery pericholecystic collection was present in $47.14 \%$ cases. $^{[15]}$

In our study, $23.81 \%$ cases of empyema of gallbladder were encountered which appeared as reddish, oedematous and moderately distended organ containing stones and pus. $7.14 \%$ of gangrenous cholecystitis was present in this study group as gall bladder appeared dark green-black in colour. Fistulous connection with gut (duodenum and transverse colon) was present in $4.76 \%$ of the cases (TABLE III). The results are in correlation with study by Gagie $\mathrm{N}$ et al who concluded that $20.43 \%$ cases were empyema and $12.9 \%$ cases had gangrene. ${ }^{[16]}$

\section{Table III: Intra-operative findings}

\begin{tabular}{|l|c|c|}
\hline Findings & $\begin{array}{c}\text { No. of Patients } \\
(\mathbf{n = 4 2})\end{array}$ & Percentage \\
\hline Adhesions & 40 & 95.24 \\
\hline Increased Wall Thickness & 37 & 88.09 \\
\hline Pericholecystic collection & 20 & 47.62 \\
\hline Empyema & 10 & 23.81 \\
\hline Gangrene & 3 & 7.14 \\
\hline Fistula & 2 & 4.76 \\
\hline
\end{tabular}

In this study 45 patients (90\%) had clinical features suggestive of acute cholecystitis, 44 patients $(88 \%)$ were diagnosed as acute cholecystitis radiologically (on Ultrasonography/CT scan/HIDA) and 42 patients (84\%) were confirmed as acute cholecystitis intraoperatively. 37 patients presented clinically as acute cholecystitis, were diagnosed as acute cholecystitits radiologically and confirmed as acute cholecystitis intraoperatively. 38 patients had clinical features of acute cholecystitis and were confirmed intraoperatively as acute cholecystitis. 41 patients had probable diagnosis of acute cholecystitis on radiological investigation and were confirmed as acute cholecystitis intraoperatively.

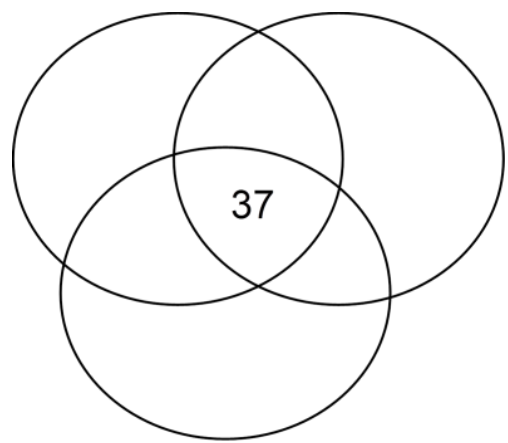

Clinically, radiologically and intraoperatively positive cases

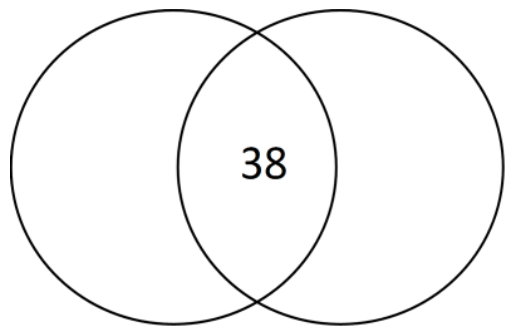

Clinically and intraoperatively positive cases

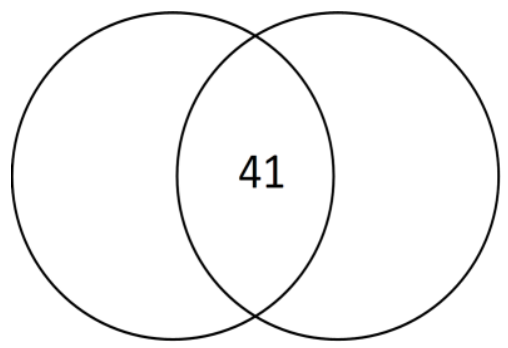

Radiologically and intraoperatively positive cases

\section{Limitations}

Sample size was small. Larger sample size is required for better analysis and results.

\section{Conclusions}

The number of patients presenting with acute cholecystitis is increasing because of the increased awareness, though some patients still visit local practitioners for treatment. The history and clinical examination along with radiological investigations is necessary to treat and manage the cases of acute cholecystitis. Surgery (cholecystectomy) remains the mainstay for treatment. With improved healthcare facilities and newer techniques, complications have declined substantially with reduced mortality and morbidity. 


\section{Bibliography}

[1] Strasberg, SM (26 June 2008). "Clinical practice. Acute calculous cholecystitis". The oNew England Journal of Medicine. 358 (26): 2804-11.

[2] Sleisenger and Fordtran's Gastrointestinal and Liver Disease: Pathophysiology, Diagnosis, Management (10 ed.). Elsevier Health Sciences. 2015. p. 1154.

[3] Ansaloni, L (2016). "2016 WSES guidelines on acute calculous cholecystitis". World Journal of Emergency Surgery: WJES. 11: 25.

[4] Greenberger N.J., Paumgartner G (2012). Chapter 311. Diseases of the Gallbladder and Bile Ducts. In Longo D.L., Fauci A.S., Kasper D.L., Hauser S.L., Jameson J, Loscalzo J (Eds), Harrison's Principles of Internal Medicine, $18 \mathrm{e}$

[5] Strasberg SM (2008). "Acute Calculous Cholecystitis". New England Journal of Medicine. 358 (26): 2804-2811.

[6] Song G, Bian W, Zeng X, Zhou J, Luo Y, Tian X. Laparoscopic cholecystectomy for acute cholecystitis: early or delayed?: Evidence from a systematic review of discordant meta-analyses. Medicine 2016;95(23):e3835.

[7] Kimura, Yasutoshi; Takada, Tadahiro; Kawarada, Yoshifumi; Nimura, Yuji; Hirata, Koichi; Sekimoto, Miho; Yoshida, Masahiro; Mayumi, Toshihiko; Wada, Keita (2016-12-12). "Definitions, pathophysiology, and epidemiology of acute cholangitis and cholecystitis: Tokyo Guidelines". Journal of Hepato-Biliary-Pancreatic Surgery. 14 (1): 15-26.
[8] Hwang H, Marsh I, Doyle J. Does ultrasonography accurately diagnose acute cholecystitis? Improving diagnostic accuracy based on a review at a regional hospital. Canadian Journal of Surgery. 2014;2014 Jun(57(3):162-168.

[9] Singh R, Jain A, Tyagi N. Int Surg J. 2016 Nov;3(4):2233-2238.

[10] Rains AJH, Ritchie HD. The gall bladder and the bile duct, Bailey and Love's Short Practice of surgery, HK Lewis and Co. Ltd., London, 17th Ed.; 1978:878-908

[11] Sangma MMB, Marak F. Int Surg J. 2016 May;3(2):914920.

[12] Alan A B, Anand B, Julian K, Clinton S B. Cholecystitis Clinical Presentation. e-medicine Medscape. 2017

[13] David F, Charlotte M, Brice R, Hassene H, Thierry Y, Jean-Marc R. Acute Cholecystitis: Preoperative CT Can Help the Surgeon Consider Conversion from Laparoscopic to Open Cholecystectomy. RSNA JournalRadiology. 2012;263(1):128-138.

[14] Rosen CL, Brown DF, Chang Y, Moore C, Averill NJ, Arkoff LJ. Ultrasonography by emergency physicians in patients with suspected cholecystitis. Am J Emerg Med. 2001 Jan. 19 (1):32-6.

[15] Mika S, Ahmad M, Nadir R, Alicia N, Abdel-Rauf Z. Sonographic Diagnosis of Complicated Cholecystitis. Journal of Ultrasound In Medicine. 2015;34(12):22312236.

[16] Gagie N, Frey CF, Gaines R. Acute cholecystitis, Surg. Gynecol. Obstet. 1975:140(6):868-74. 